\title{
Stage IIIA Vulvar Cancer AJCC v8
}

National Cancer Institute

\section{Source}

National Cancer Institute. Stage IIIA Vulvar Cancer A/CC v8. NCI Thesaurus. Code C139624.

Stage IIIA includes: T1-T2, N1, M0. T1: T umor confined to the vulva and/or perineum. Multifocal lesions should be designated as such. The largest lesion or the lesion with the greatest depth of invasion will be the target lesion identified to address the highest pT stage. Depth of invasion is defined as the measurement of the tumor from the epithelialstromal junction of the adjacent most superficial dermal papilla to the deepest point of invasion. T2: T umor of any size with extension to adjacent perineal structures (lower/distal third of the urethra, lower/distal third of the vagina, anal involvement). N1: Regional lymph node metastasis with one or two lymph node metastases each less than $5 \mathrm{~mm}$, or one lymph node metastasis equal to $5 \mathrm{~mm}$. M0: No distant metastasis. (AJCC 8th Ed.) 